\title{
ESTIMACIÓN DE LA TÉCNICA IN VITRO DE GASES FRENTE A OTRAS TÉCNICAS DE DIGESTIBILIDAD
}

\author{
Javier Vargas-Bayona ${ }^{\star}, \mathrm{MVZ}_{1}$, Germán Mejía-Porras, MV, Esp. ${ }_{1}$, \\ Julia Bedoya-Mashuth, MVZ, Esp., M.Sc. (c), Juan Felipe Gómez-Patiño MVZ
}

Facultad de Medicina Veterinaria y Zootecnia, Universidad Cooperativa de Colombia, sede Bucaramanga, Colombia

Recibido: 21 de marzo del 2013 Aprobado: 17 de abril del 2013

*Autor de correspondencia: Javier Vargas Bayona, Grupo de Investigación en Ciencias Animales (Grica), Facultad de Medicina Veterinaria y Zootecnia, Universidad Cooperativa de Colombia, Bucaramanga, Colombia, calle 30A n. ${ }^{\circ 33-51,(57)} 7$ 6356624, correo electrónico: javier.vargasb@campusucc.edu.co

Cómo citar este artículo: Vargas-Bayona J, Mejía-Porras G, Bedoya-Mashuth J, Gómez-Patiño JF. Estimación de la técnica in vitro de gases frente a otras técnicas de digestibilidad. Spei Domus. 2013; 9(18): 59-70.

Resumen. Para estimar el metabolismo de los alimentos consumidos por rumiantes, se han creado diversas técnicas de análisis nutricional que aportan información valiosa a la investigación en nutrición animal, buscando, entre otros, criterios para aumentar la eficiencia productiva en los sistemas tropicales de producción, considerando que los forrajes del trópico son la base de alimentación en rumiantes. De ahí la importancia de revisar y documentar sobre las diferentes técnicas de digestibilidad, para orientar hacia la mejor elección, a partir de referentes nacionales e internacionales. El objetivo de este reporte fue realizar una revisión de literatura sobre las técnicas de digestibilidad de forrajes utilizadas para estimar el comportamiento general de los alimentos para rumiantes. Para este fueron revisadas y analizadas más de 50 publicaciones, que arrojaron información sobre técnicas de digestibilidad in vivo, in situ e in vitro, y los alcances y limitaciones de estas. Como resultado se puede inferir que las técnicas se han convertido en una herramienta de gran importancia en el bioensayo, dada la facilidad para desarrollarla, costos reducidos, aplicación en el ámbito local, información valiosa que aporta, teniendo en cuenta que son escasos los estudios sobre forrajes tropicales. A partir de los hallazgos encontrados sobre las técnicas de digestibilidad de forrajes, se puede concluir que la técnica de digestibilidad in vitro de producción de gases es la herramienta más versátil; presenta procedimientos didácticos y accesibles; acarrea menos costos; además representa una alternativa más compatible para las legislaciones de bienestar animal, al usar las heces como inóculo. Sin embargo, es necesario realizar más estudios sobre los inóculos utilizados, debido a que los protocolos no están estandarizados y a que el comportamiento cinético en los ensayos realizados no ha arrojado los resultados esperados.

Palabras clave: bioensayo, inóculo, licor ruminal, rumiantes, transductor de presión.

Comparison of the In vitro Gas Technique to Other Digestibility Techniques

\begin{abstract}
To estimate the metabolism of the food consumed by ruminants, various nutritional analysis techniques have been developed to provide valuable information for research into animal nutrition. Objectives include criteria to increase productive efficiency in tropical production systems, particularly when tropical forages are the nutritional basis for ruminants. Thus, the motivation to review and document different digestibility techniques to determine the best choice among national and international references. The aim was to review the literature about forage digestibility techniques developed for estimating the overall behavior of foods in ruminants. More than 50 references were reviewed, obtaining information on in vivo, in situ and in vitro digestibility techniques along with their limitations and advantages. It can thus be inferred that these techniques have become very important biotrial tools, given that they are easy to carry out, reduce costs and can be applied locally. They provide valuable information, particularly in view of the small number of studies on tropical forages. Based on the forage digestibility techniques findings, we may conclude that the in vitro gas production digestibility technique is the most versatile tool, with accessible and instructive procedures and at lower cost; it is also more compatible with animal welfare regulations because it uses feces as inoculums. However, further studies need to be
\end{abstract}

\section{Estimação da Técnica In vitro de gases em relação a outras técnicas de digestibilidade}

Resumo. Para estimar o metabolismo dos alimentos consumidos por ruminantes, foram criadas diversas técnicas de análise nutricional que contribuem com informação valiosa para a pesquisa em nutrição animal e buscam, entre outros, critérios para aumentar a eficiência produtiva nos sistemas tropicais de produção, considerando que as forragens do trópico são a base de alimentação em ruminantes. Daí a importância de revisar e documentar sobre as diferentes técnicas de digestibilidade, para orientar à melhor escolha, a partir de referentes nacionais e internacionais. O objetivo desse relatório foi realizar uma revisão de literatura sobre as técnicas de digestibilidade de forragens utilizadas para estimar o comportamento geral dos alimentos para ruminantes. Para isso, foram revisadas e analisadas mais de 50 publicações, que produziram informação sobre técnicas de digestibilidade In vivo, In situ e In vitro, e os alcances e limitações destas. Como resultado, pode-se inferir que as técnicas vêm se convertendo em uma ferramenta de grande importância no bioensaio, dada a facilidade para desenvolvê-la, custos reduzidos, aplicação no âmbito local, informação valiosa que contribui, considerando que são escassos os estudos sobre forragens tropicais. A partir das descobertas encontradas sobre as técnicas de digestibilidade de forragens, pode-se concluir que a técnica de digestibilidade In vitro de produção de gases é a 
carried out regarding the inoculums used, given the need for protocol standardization and because kinetic behavior in the trials has not produced the expected results.

Keywords: bioassay, inoculums, ruminal fluid, ruminants, pressure transducer. ferramenta mais versátil; apresenta procedimentos didáticos e acessíveis acarreta menos custos; além disso, representa uma alternativa mais compatível para as legislações de bem-estar animal, ao usar as fezes como inóculo. Contudo, é necessário realizar mais estudos sobre os inóculos utilizados, devido a que os protocolos não estão padronizados e a que o comportamento cinético nos ensaios realizados não produziu os resultados esperados.

Palavras-chave: bioensaio, inóculo, líquido ruminal, ruminantes, transdutor de pressão.

Ørskov y colaboradores, el cual se acerca más a los métodos de digestibilidad in situ que son realizados en las investigaciones actuales [4].

En cuanto al método in vitro, este se empezó a desarrollar desde la década de los sesenta, buscando determinar la dinámica de degradación de la materia orgánica (Mо). Tilley y Terry realizaron el primer ensayo in vitro para la degradación de materia seca de 146 forrajes, utilizando líquido ruminal de bovinos y pepsina ácida. Posteriormente, otros experimentos fueron más específicos, encargándose de la degradación de la pared celular [5].

Goering y Van Soest realizaron un experimento con bovinos y búfalos a los cuales se había realizado fistulación ruminal; estos últimos fueron alimentados con Pennisetum purpureum y Dactylis glomerata. Por medio de técnicas in vitro, analizaron la degradabilidad de 22 forrajes diferentes, teniendo en cuenta periodos para el análisis (48, 72 y 96 horas). De esta manera se pudo determinar que la tasa de fermentación varía si se tiene en cuenta la especie de rumiante, pues con ganado europeo (Bos taurus) se obtuvo una menor fermentación que con el ganado bufalino [6].

En la década de los noventa se realizó un ensayo buscando analizar la cinética de degradación de los almidones [7]. Dicha técnica no era clasificada como de digestibilidad debido a que no ofrece información sobre la cinética de estos forrajes en el rumen. Comparado con los trabajos mencionados anteriormente, a finales de la década de los setenta se fue desarrollado un método en el cual se incubaron forrajes con microorganismos del rumen, los cuales liberaban gas que fue tomado como una medida indirecta de su digestibilidad y contenido de energía metabolizable [8]. Esta técnica de producción de gas se constituye en una metodología promisoria para medir las tasas de digestión de las fracciones solubles e insolubles de los forrajes para rumiantes; permite analizar una amplia gama de alimentos ya sean pastos, forrajes o inclusive granos, debido a que su condición in vitro posibilita una manipulación fácil
Proyecto realizado por el Grupo de Investigación en Ciencias males (Grica), y financiado por el fondo del Comité Nacional para el Desarrollo de la Investigación, Conadi, de la Universidad Cooperativa de Colombia. 
de los sustratos porque se encuentran en un ambiente externo al animal, sin riesgos de escapes de la muestra dentro de los frascos por incubar. Por tanto, realizar este tipo de técnicas de digestibilidad permitirá obtener resultados de los valores requeridos por los nuevos sistemas de evaluación de alimentos para predecir el desempeño del animal con respecto a las dietas y a las raciones administradas de un alimento en específico.

En experimentos más recientes, que incluyen la técnica de producción de gases como la medida para estimar la digestión de los componentes de los alimentos y predecir la digestibilidad, se han incorporado métodos que permiten facilitar más el trabajo. Estos son los métodos semiautomáticos o automáticos, los cuales utilizan dispositivos electrónicos como transductores de presión y computadores, que posibilitan una recolección y almacenamiento más exacto de los datos de producción de gas. Teniendo en cuenta las ventajas que este método brinda, permite que haya una mayor eficacia y exactitud en las medidas, lo que hace posible realizar más repeticiones que facilitan perfiles más acertados, como lo reportan Mauricio y colaboradores [9] y Posada y Rosero [10]. Los primeros investigadores en realizar este tipo de experimento fueron Pell y Schofield [11] y Theodoru y colaboradores [12].

\section{Métodos de digestibilidad in situ de forrajes}

Los métodos para evaluar la digestibilidad in situ de forrajes son el resultado de muchos años de investigación y pruebas de ensayo y error, partiendo desde el material que se va a usar para las bolsas que se ingresan en el rumen, la porosidad que está ligada al material usado, el tamaño de las muestras, la posición de las bolsas en el rumen, el número de bolsas por incubar, entre otros.

Después de intentar con múltiples recursos incluyendo retazos de un paracaídas viejo, la primera prueba de digestibilidad in situ fue realizada por Ørskov y colaboradores, quienes establecieron que el nylon es el material más adecuado para hacer las bolsas que se introducen en el rumen, debido a que cuentan con la porosidad y resistencia específicas para poder someterse a las condiciones de la digestión y fermentación ruminal, sin alterar los resultados del bioensayo [4].

Luego Nocek [13], basándose en la técnica de digestibilidad in situ, determinó la digestión de la materia orgánica (MO) teniendo en cuenta que está formada por la pared celular. Hizo énfasis en requisitos específicos y condiciones especiales que permiten realizar dicho ensayo. Para esto tuvo en cuenta puntos clave como:

- Porosidad de las bolsas de nylon (40 a $60 \mu \mathrm{m})$.

- Tamaño de las partículas de la muestra: granos de cereal y productos de fibra, $5 \mathrm{~mm}$; henos ( $>80 \% \mathrm{MS}$ ), $5 \mathrm{~mm}$; silos (secados al aire 60-70\% materia seca [Ms] congelados en seco y luego molidos), $5 \mathrm{~mm}$.

- Tamaño de la muestra con respecto a la superficie de la bolsa (10 a $20 \mathrm{mg} / \mathrm{cm}^{2}$ ), dieta (alimento para satisfacer las necesidades de dieta del animal, documentar los componentes de la ración, administrar ad libitum).

- Animal o unidad experimental (usar cada animal con las determinaciones de la técnica por analizar, al menos dos replicaciones si sólo se usara un solo animal, manejar los mismos tiempos de alimentación y periodos de inserción de las bolsas en cada animal).

- Incubación preruminal (sumergir las bolsas en buffer o en agua antes de ingresarlas en el rumen).

- Inserción de las bolsas (ingresar las bolsas con intervalos y tiempos específicos lo mismo que en el momento de retirarlas).

- Lavado posruminal (se puede realizar con agua de grifo lavando las bolsas hasta que el agua salga clara, manipulándolas de manera moderada).

- Tiempos de incubación (de 0 a 6 horas: de 3 a 6 puntos de tiempo, de 6 a 24 horas: de 3 a 6 veces, $>25$ horas: 6 a 12 intervalos).

Nocek [13] determinó que la digestibilidad de la materia orgánica (MO) se aproxima a un $80 \%$ en el rumen; esto puede ser una referencia para comparar la digestibilidad de otros forrajes [14].

Los sacos de nylon ${ }^{\circ}$ con los sustratos por analizar son introducidos en el rumen, previa fistulación ruminal del animal. Los forrajes experimentales son sometidos a un proceso de deshidratación y molido. Los sacos serán extraídos a periodos predeterminados. Diferentes autores han descrito periodos en los cuales se puede realizar la técnica basados en la publicación de Nocek [13]. Zanton y Heinrichs, por ejemplo, utilizaron periodos de 1, 2, 4, 8, 16, 24, 48 y 72 horas. Posteriormente, los sacos son recuperados del rumen y llevados al laboratorio para determinar la digestión de la materia seca y estimar los valores de digestibilidad [15].

Igualmente, se puede estimar la digestibilidad de fracciones como fibra detergente neutra (FDN), materia seca (MS), materia orgánica (MO) [14, 16-18], por medio 
de análisis bromatológico de los residuos presentes en los sacos.

Por otro lado, los sacos de nylon no son necesariamente el único material usado para este tipo de ensayo. Otros materiales han sido tenidos en cuenta para realizar el estudio. En los ensayos de Winterholler y colaboradores fue utilizado un material conocido como Dacron, un polyester comercial que proporciona la resistencia y adaptabilidad para realizar el ensayo, pero a un costo es más elevado. Por tanto, no es un material de uso convencional [19]. Hay también trabajos con TNT (tejido no tejido).

Los experimentos que se han realizado para validar la técnica in situ como método para estimar la degradabilidad de la pared celular de los forrajes, se fundamentan en la comparación del flujo duodenal de los carbohidratos estructurales en estudios in vivo y degradabilidad efectiva calculada a partir de la degradación in situ y la tasa de pasaje.

Noziére y Michalet-Doreau reportan que la utilización de la técnica in situ conduce a una determinación de la digestión de la pared celular en el rumen [18]. Este cálculo de la digestión ruminal puede ser atribuida a una estimación de la tasa de digestión [20] o al bajo número de bacterias celulolíticas [21] y la baja actividad de las enzimas fibrolíticas dentro de los sacos de nylon comparados con las condiciones normales del rumen durante el proceso de incubación [22].

Además de la determinación de la digestibilidad y degradación de gran parte de los nutrientes de los alimentos consumidos por los rumiantes, la técnica in situ también ha sido empleada como método para predecir las porciones no digeribles de los forrajes, considerando los residuos de materia seca (Ms) y de la pared celular como estimadores [23].

Como es evidente, la técnica de digestibilidad in situ se caracteriza por analizar varios nutrimentos al tiempo, haciéndola una técnica de gran importancia para la nutrición animal y la zootecnia. Sin embargo, la necesidad de poseer animales con fístulas del rumen es una limitante, sumado a que esta técnica se realiza en dos momentos diferentes, uno es la actividad que se realiza en el animal y el segundo los análisis externos que están ligados a los laboratorios de nutrición animal en los cuales se hacen análisis bromatológicos posteriores a la extracción de las muestras del rumen. De la misma forma, el no contar con un laboratorio especializado es otra limitante para la realización del ensayo. Aunque existe la posibilidad de enviar las muestras a laboratorios que presten el servicio, esto acarrearía más costos de los estimados, comparándola con la técnica de digestibilidad in vitro de producción de gases, en la que los resultados se obtienen en el mismo lugar de la incubación por medio del uso del transductor de presión.

\section{Métodos de digestibilidad in vivo de forrajes}

Los métodos de digestibilidad in vivo son métodos un poco más dispendiosos, debido a que se deben establecer dietas completas para un grupo de animales, y estos deben ser sometidos a condiciones de jaulas metabólicas para el consumo de un alimento específico y sus heces recolectadas para realizar los estudios respectivos. Estas jaulas metabólicas corresponden a compartimentos en los cuales el animal sólo tendrá acceso al alimento por estudiar y agua, además de permitir la recolección de las heces y la orina, que serán sometidas a pruebas específicas para determinar los nutrimentos producto de la digestión: Ms, ceniza, proteína, extracto etéreo, fibra cruda, fibra total. Estas pruebas, así mismo, se realizan para el alimento ofrecido y el alimento rechazado por el animal, tomado directamente desde la jaula metabólica $[24,25]$.

En esta técnica, si se tienen en cuenta los conceptos básicos de digestibilidad, para determinarla simplemente se tendría que obtener la diferencia entre los nutrimentos consumidos y los que aparecen en las heces, midiendo cada clase de nutrimento; todo esto facilitado por un marcador o colorante que indica el tránsito del alimento desde el inicio hasta final del tracto digestivo. En el caso de la medición de la digestibilidad en los rumiantes, tiende a ser más complicada que una simple recolección de heces, debido a la naturaleza del rumen y sus procesos [24, 26, 27].

Estos procesos en rumiantes pueden ser explicados considerando: como los alimentos consumidos no pasan secuencialmente por el aparato digestivo, sino que tienen que someterse a un proceso de rumia, es decir, al llegar al rumen este va ser regurgitado y remasticado una y otra vez para volver de nuevo al rumen, es imposible determinar el tiempo de digestión de una porción o la totalidad del alimento suministrado en un momento específico, ya que habrá porciones del alimento que durarán más tiempo en proceso de fermentación ruminal, durante horas o incluso hasta días.

Por tanto, para garantizar el éxito de una prueba de digestibilidad in vivo en rumiantes, se debe someter 
al animal a un periodo de acostumbramiento mínimo de siete días, en el cual sólo se ofrecerá el forraje experimental para permitir que desarrolle una población de bacterias ruminales específicas y necesarias para digerir adecuadamente el alimento de experimentación [27].

Ensayos como estos han sido realizados en otras especies como los caprinos, en los cuales los costos no son tan altos como en bovinos, debido especialmente a que las jaulas metabólicas son más pequeñas.

Galina y colaboradores en su trabajo reportan que determinaron la Ms, el nitrógeno (N), la MO, la FND, la celulosa y la hemicelulosa, recolectando las heces que fueron sometidas a procesos de secado en una estufa de aire forzado a $70^{\circ} \mathrm{C}$ por 36 horas, y su almacenamiento en botellas herméticas. A la orina recolectada durante cinco días consecutivos se le fue agregando ácido sulfúrico (10\%) para mantener el $\mathrm{pH}$ por debajo de 3 ; luego se tomaron $100 \mathrm{ml}$ y se congelaron a $-20^{\circ} \mathrm{C}$ hasta el momento de los análisis. Adicionalmente, midieron la velocidad de pasaje con la fibra Cr-mordante, dada a través del alimento y recuperada en las heces, en un periodo de 24 y 48 horas [28].

En teoría, parece un proceso simple el recoger las heces y la orina; pero al momento de llevarlo a la práctica, es evidente que se hace tedioso y costoso. Algunas instituciones cuentan con colectores mecánicos costosos. Cuando este procedimiento es realizado con vacas es más difícil la recolección y separación de las heces y la orina; si estas llegasen a mezclarse causarían un error suficiente como para anular la prueba. Todo lo anterior evidencia la dificultad para realizar una prueba de digestibilidad in vivo [28].

Se han desarrollado métodos que disminuyen un poco estos obstáculos y de alguna manera amortiguan los costos que acarrean. El principio básico se basa en usar una sustancia que pase por el sistema digestivo con una velocidad más o menos constante y sin absorción; para ello se utilizan marcadores como el óxido crómico $\left(\mathrm{Cr}_{2} \mathrm{O}_{3}\right)$, de uso restringido por ser cancerígeno; se puede administrar de diversas maneras, ya sea mezclado con el alimento, en cápsulas, homogeneizado en aceite, suministrado en pastillas o en papel impregnado con el mismo. Si bien es de alto costo, es una de las soluciones más prácticas para determinar el pasaje del alimento a través del tracto digestivo de los rumiantes. Otras sustancias que no son absorbidas y que pueden ser utilizadas como indicadores son sustancias que se encuentran formando parte de las plantas que constituyen el alimento, como la lignina, el nitrógeno y los cromógenos. De esta manera, las heces serán recolectadas con el respectivo indicador y se procederá a analizar, con procedimientos similares a los mencionados previamente, los diferentes nutrimentos presentes en las heces y compararlos con los de los alimentos consumidos [29].

Es evidente que el proceso in vivo es extenso, tedioso y costoso, por lo cual, en la actualidad, procesos innovadores como los de digestibilidad in vitro, por el método de producción de gases, son más prácticos y acarrean menos costos.

\section{Métodos de digestibilidad in vitro de forrajes}

Los métodos de digestibilidad de forrajes in vitro aparecen en la década de los sesenta con las investigaciones y ensayos de Tilley, quien, usando el licor ruminal de bovinos fistulados, realizó la degradabilidad in vitro de 146 forrajes [5]. Este tipo de pruebas aportan información acerca de la desaparición de la materia seca por medio de la simulación de digestiones sucesivas. Sin embargo, para esos primeros ensayos, la técnica no ofrecía ninguna información adicional, toda vez que el concepto de la relación entre la cantidad de gas liberado y la digestibilidad de los forrajes no aparecería hasta finales de siglo.

A partir de estos ensayos se hicieron modificaciones que permitieron perfeccionar la técnica hasta la obtención de lecturas a través de jeringas y transductores de presión $[8,12]$.

\section{Cultivos de microorganismos ruminales de corta duración}

\section{Técnica de gases}

Las investigaciones y ensayos realizados a través de los años han determinado que la cinética de digestión que esta técnica permite realizar puede ser evaluada por la desaparición de la FDN o por la medición del gas liberado en la fermentación. Cuando estos métodos son realizados para determinar las características intrínsecas de los alimentos, es importante tener en cuenta que estos mismos no impongan limitaciones en la digestión [30]. También hay que tener en cuenta las variaciones entre los animales, la especie donante, el manejo de la alimentación y el tiempo de recolección del inóculo, que pueden afectar la digestibilidad in vitro. Por tanto, este tipo de método aún se encuentra en una extensa y constante revisión y reevaluación [31]. 
Actualmente, para la cuantificación y medición del gas liberado son utilizados métodos automatizados más prácticos y eficientes con respecto a otros, como las jeringas graduadas $[8,32]$. Con frecuencia, estas mediciones son realizadas con sensores electrónicos de presión, los cuales miden la presión de gas liberado en la parte superior de los frascos $[12,31]$ y equipos automáticos para el registro de datos. Estas mediciones son realizadas con intervalos de tiempo específicos, que permitirán establecer y estimar la cinética de degradación de los forrajes por estudiar $(2,4,6,8,10$, $12,15,19,24,30,36,48,72$ y 96 horas) [10]. Así mismo, otros autores [33] realizaron experimentos utilizando dispositivos semiautomáticos, que con la ayuda de transductores de presión hicieron que la recolección de las lecturas fuera más rápida.

Sin embargo, los primeros experimentos con equipos automáticos no registraban la presión ni el volumen de gas liberado, sino que establecían una conversión matemática a partir del peso que ganaban los frascos a medida que el gas era liberado dentro de ellos [34].

En la actualidad, en el país se están utilizando métodos que permiten realizar unas lecturas de datos automatizados o semiautomatizados directamente desde los inóculos, lo que permite una fácil recolección de un suficiente número de observaciones para establecer un parámetro de estimación más exacto. No obstante, se requiere una ecuación de regresión que relacione volumen con presión de acuerdo con las condiciones de altura sobre nivel del mar, requisito indispensable para la técnica.

Además de este tipo de ecuaciones que se usan en la práctica del bioensayo, en el constante trabajo de campo se han encontrado cantidad de problemas con la técnica de producción de gas, como variaciones en la composición de los gases producidos en la fermentación [31], errores causados por el tamaño de las muestras (sustratos), la inhabilidad del sistema para distinguir los diferentes sustratos y la producción de amoniaco en el gas liberado. Sin embargo, muchos de estos problemas pueden ser corregidos aislando químicamente la FDN y calculando su comportamiento en la digestión in vitro; comparaciones realizadas que evalúan el desempeño con los forrajes enteros y la FDN aislada demuestran comportamientos similares en la cinética de digestión [35].

Otro de los posibles contratiempos para el desarrollo del método in vitro es la necesidad de contar con licor ruminal, el cual es extraído necesariamente de animales con fistulación ruminal, proceso quirúrgico sujeto a la legislación de bienestar animal, en países como Colombia. Por ello los investigadores han propuesto usar inóculo de heces de ganado bovino, con el fin de proponer una alternativa para realizar los procedimientos sin fístula ruminal $[9,10]$.

Para los métodos de degradación in vitro son necesarios elementos con ciertas condiciones específicas para que se pueda llevar a cabo de manera exitosa el ensayo: los sustratos forrajeros que se van a utilizar deben ser deshidratados y pasados por un molino analítico de partículas de $1 \mathrm{~mm}$, que permite mayor degradación por actividad microbiana ruminal [36]; un buffer que cumpla con las condiciones de $\mathrm{pH}>6$, adecuado para la supervivencia y desempeño de los microorganismos del rumen. Algunos científicos describen que para mantener este tipo de $\mathrm{pH}$ es necesario un buffer que contenga una mezcla de bicarbonato-fosfato, así la producción de gas se desarrolla con mayor facilidad [11]. Para que este buffer sea un medio apropiado para los microorganismos del rumen, el inóculo debe ser previamente saturado con $\mathrm{CO}_{2}$, para disminuir la posibilidad de aumento del potencial redox en los componentes del inóculo, es decir, disminuir los estados de oxidación de algunos de los componentes y la presencia de oxígeno; la ausencia de anaerobiosis trae como resultado la pérdida de bacterias celulolíticas y amilolíticas, lo que disminuye notablemente la actividad de degradación dentro del inóculo.

Otros autores como Grants y Mertens reportan que el gaseo continuo con $\mathrm{CO}_{2}$ permite que haya una colonización del sustrato en menor tiempo y, por lo tanto, una mayor digestión de la FDN [37]. Otro factor de gran importancia que se debe tener en cuenta es una incubadora que garantice temperatura constante de $39^{\circ} \mathrm{C}$, similar a la temperatura corporal del donador del licor ruminal, ya que la actividad microbiana, las presiones y el volumen de gas son muy sensibles a cambios en la temperatura de incubación [38].

En la incubación es importante la agitación periódica de los frascos, debido a que la naturaleza del $\mathrm{CO}_{2}$ tiende a formar soluciones supersaturadas en medios acuosos, lo que traerá como resultado lecturas de presión y volumen incorrectos. Además, el aumento de presión hace que los tapones de los frascos se disparen perdiendo la medida de presión; una leve agitación periódica de los frascos reduce esta tendencia al aumento de presión [38].

Los resultados de la recolección de las presiones tomadas por medio de un transductor de presión son lecturas en PSI (Pounds per Inch Square o libras por 
pulgada cuadrada) [36]. Es necesario ajustar estas lecturas mediante ecuaciones que permiten estimar la extensión y la cinética de degradación del alimento durante el proceso fermentativo [12].

Para entender mejor la naturaleza del gas producido es necesario razonar sobre los siguientes conceptos: la energía utilizada y necesaria para el crecimiento microbiano es derivada de la fermentación de los carbohidratos, principalmente almidón y celulosa, cuya digestión anaerobia produce ácidos grasos volátiles (AGV), succinato, formalato, lactato, etanol, dióxido de carbono $\left(\mathrm{CO}_{2}\right)$, metano $\left(\mathrm{CH}_{4}\right)$ y trazas de hidrógeno $\left(\mathrm{H}_{2}\right)$, y también aportan esqueletos de carbono esenciales para la síntesis de biomasa microbiana $[39,40]$. La producción de gas de la fermentación de la proteína es relativamente pequeña, y la derivada de la grasa es insignificante [41]. Entonces se podría decir que la cantidad de gas liberado depende de la cantidad de sustrato fermentado y la cantidad y proporciones molares de AGV [42].

Es importante resaltar que el volumen de gas producido durante los eventos fermentativos del alimento en el fluido ruminal sólo constituye el reflejo de los eventos que ocurren en el rumen. Los alcances de la técnica superan este nivel y los resultados de ella han sido comparados y relacionados con la digestibilidad in vivo en el tracto digestivo total [8]. Por tanto, se pueden plantear curvas de producción de gas que permitan comparar el comportamiento de los diferentes sustratos o alimentos durante los ensayos, además de permitir la realización al tiempo de un gran número de repeticiones que conducen a la obtención de perfiles más detallados y exactos con respecto a la cinética de degradación [36].

\section{Método de Daisy II}

Este método utiliza la técnica in vitro de Goering y Van Soest [6] por medio de un aparato incubador llamado DaisyII ${ }^{\circ}$-Ankom Technology; permite estimar la digestión de la materia seca (MS) utilizando tiempos de incubación de 12, 24, 48, 72 y 84 horas. El Daisy II realiza la digestión en cuatro vasijas a las cuales se inoculan dos litros de licor ruminal diluido al 20\%; luego se realiza la determinación de la degradación de la FDA y la FDN por medio de otros equipos [43].

Este método in vitro es otra alternativa para obtener la cinética de degradación de forrajes en los laboratorios, pero a pesar de ser una herramienta más sencilla que Rusitec, descrita después, carece de lecturas de producción de gas; además los costos son muy elevados. En contraste, la técnica de producción de gases tiene un gran número de indicadores, costos más reducidos y su versatilidad la convierte en la mejor elección para realizar este tipo de bioensayos.

\section{Cultivos de microorganismos ruminales de larga duración (CMRLD) Rusitec}

Las diversas técnicas de digestibilidad han permitido a los diferentes investigadores utilizar sus conocimientos para recrear las condiciones ruminales en una gran variedad de métodos. Rusitec (Rumen Simulation Technique), o técnica de simulación del rumen, es una variante de las técnicas de digestibilidad in vitro que recrea dentro de un aparato las condiciones del rumen, permitiendo medir la degradación de los forrajes, la recolección del gas liberado por esta y el efluente que se produce en los frascos.

Este sistema trabaja con cuatro recipientes que están dispuestos en una base que contiene agua atemperada a $39{ }^{\circ} \mathrm{C}$ para mantener las condiciones de temperatura similares a las del organismo animal [44].

Cada frasco está dispuesto con el contenido ruminal y el sustrato que se va a analizar dentro de bolsas de nylon ${ }^{\circledR}$; tienen válvulas de entrada y salida. Las de entrada permiten la inoculación de saliva artificial a los frascos recreando un flujo constante como en el proceso de la rumia. Las válvulas de salida recolectan el efluente producido por la fermentación y digestión de la materia seca, la proteína del alimento y la proteína microbiana. El gas producido se dispone en bolsas y puede ser medido por dispositivos (manómetro) que calculan la presión generada, y los gases $\left(\mathrm{CO}_{2}, \mathrm{CH}_{4}, \mathrm{NH}_{4}\right.$ y AGV) son analizados por cromatografía de gases [44]. Por lo regular, esta técnica utiliza la inoculación constante de bolsas de nylon ${ }^{\circledR}$ con material (forraje) nuevo y con material previamente inoculado durante dos días.

Estos procedimientos se realizan por tiempos prolongados y es necesario disponer de todos los equipos para realizar la prueba; de lo contrario la técnica es imposible de hacer. Para poder manipular el equipo es necesaria la presencia del personal técnico capacitado, lo cual hace que el nivel de dificultad de la técnica sea más alto. Todos estos factores se convierten en limitaciones que hacen que la técnica de producción de gases resulte más factible para estudios de digestibilidad.

En cuanto a las ventajas de los métodos de digestibilidad in vitro de producción de gases, considerando los elementos discutidos anteriormente, este método es 
una alternativa versátil que se acomoda a cualquier tipo de alimento que pueda ser analizado, con la ventaja sobre la técnica in situ de que sólo permite el análisis de alimentos de una consistencia sólida y la presencia de animales que tengan una fístula ruminal para introducir los sacos de nylon.

Trabajos previos describen métodos de degradación in vitro de gran exactitud, así como de producción de gases, utilizando como inóculo las heces, haciendo de esta técnica la más aceptada por las legislaciones de bienestar animal $[9,10]$.

Varios autores han resaltado las ventajas de la técnica de digestibilidad in vitro de producción de gas con respecto a la técnica de digestibilidad in vivo, haciendo énfasis en los siguientes puntos: menor costo, menor tiempo para realizarla y, la más importante, la capacidad de mantener las condiciones experimentales con más precisión que los ensayos in vivo [45].

Otra de las ventajas de este tipo de ensayo es la capacidad de recolección de datos por medio de métodos semiautomáticos; es decir que las presiones liberadas en los frascos de los inóculos pueden ser medidas por medio de transductores de presión, que conectados a dispositivos electrónicos pueden almacenar dicha información, dando medidas más exactas y confiables.

Mauricio y colaboradores realizaron experimentos utilizando un transductor de presión, un convertidor de datos y un computador personal, de manera que todos los datos de las mediciones fueran registrados por un programa computarizado, lo que permitió un almacenamiento más seguro de la información, dando confiabilidad y exactitud en las medidas tomadas desde los inóculos [33]. Comparando y teniendo en cuenta el resultado y desempeño de los primeros ensayos in vitro que tomaban sus medidas por medio de jeringas graduadas [12], es evidente que es más fácil en la actualidad realizar este tipo de ensayos usando los métodos semiautomáticos en la academia, y así reforzar y aumentar las prácticas de áreas de la zootecnia como la nutrición animal. Estos métodos acarrean menores costos que los métodos de digestibilidad in vivo; además son más didácticos y usan metodologías menos complejas.

Otra característica de esta técnica es la capacidad de estimar los ácidos grasos volátiles liberados en la degradación de los forrajes por medio de procedimientos de estequiometría [46], que permiten reconocer los factores nutricionales de gran cantidad de forrajes, lo cual podría predecir el comportamiento y desempeño del consumo de estos alimentos en las producciones pecuarias, herramienta de gran utilidad para establecer dietas que permitan alcanzar los estándares requeridos por el mercado competitivo.

\section{Alcances de los métodos de digestibilidad in vitro de producción de gases}

La técnica in vitro de producción de gases ofrece la capacidad de predecir la tasa de digestión de las diferentes fracciones de carbohidratos; es útil para determinar y cuantificar diferencias nutricionales atribuidas a los métodos de preservación de especies forrajeras y estado de madurez de la planta [47], comparando el desempeño de gramíneas y leguminosas en diferentes estados de madurez y de ensilajes de estas mismas.

Los resultados de esta técnica mostraron que la utilización de los porcentajes de fibra subestiman los valores de energía líquida de los ensilajes, pues aunque ellos tuviesen los mismos porcentajes de fibra detergente ácida (FDA) que el material original, presentaron menor producción de gas. Estas diferencias son atribuídas a la pérdida de carbohidratos solubles durante el proceso fermentativo de los ensilajes. Igualmente, los ácidos grasos volátiles (AGV) presentes en los ensilajes no representan una importante fuente de energía para los microorganismos ruminales, como sí lo son los carbohidratos solubles en el material original [47].

Este tipo de ensayos nos permite evaluar la calidad de los alimentos, para detectar diferencias entre los sustratos generados por su madurez, condiciones de crecimiento, especie o cultivo y métodos de preservación [36].

Con respecto a la digestibilidad de la FDN, se ha demostrado que la producción de gases está relacionada con la desaparición de la FDN [48]. Por otra parte, experimentos realizados con granos de cereales demuestran una alta correlación entre la producción de gas in vitro y la disponibilidad del almidón en dichos granos [39]. Otros estudios encontraron que la producción de gas acumulada en 24 horas estaba correlacionada con la digestibilidad de la mo determinada in vivo.

Esta técnica permite estudiar la degradación de cada uno de los constituyentes del alimento o fracciones alimenticias (monosacáridos, pectinas, almidón, celulosa y hemicelulosa) y así se puede diferenciar qué elementos inhiben y qué otros aumentan la actividad microbiana. De esta manera se puede establecer la cinética de la fermentación, teniendo en cuenta las proporciones de partículas solubles, insolubles pero degradables, y no degradables del alimento [49]. 
La predicción del consumo es un alcance bastante significativo que también se obtiene por la técnica in vitro, lo que demuestra que el consumo de forrajes fue mejor correlacionado con sus características de degradabilidad ruminal que con la digestibilidad en el tracto digestivo total [50]. Estudios realizados por Liu y colaboradores [51] determinaron que esta técnica ha sido utilizada como una medida de la degradación ruminal de los alimentos y como un indicador del consumo de Ms digestible.

Por tanto, la técnica in vitro es una herramienta de vital importancia para las ciencias agropecuarias, al estimar la capacidad de degradación de ciertos forrajes que componen la dieta de las especies ovinas, caprinas y bovinas del país, que serán fuentes de proteína para las poblaciones humanas en las diferentes regiones del mundo.

Además, las especies forrajeras tropicales carecen de estudios que determinen datos específicos como la extensión y magnitud de la fermentación ruminal, la producción de gases relacionados con el efecto invernadero $\left(\mathrm{CH}_{4}\right)$, así como su digestibilidad, que no ha permitido la determinación real de su valor nutricional. Finalmente, a pesar de ser una técnica con cierto nivel de complejidad, ofrece información bastante productiva, en especial al ser incluida en ensayos que se hagan en pregrado.

\section{Limitaciones de los métodos de digestibilidad in vitro de producción de gases}

Una premisa para la investigación con esta técnica, compartida por la gran mayoría de investigadores, es la falta de conformidad y uniformidad en las metodologías; esto es algo en lo que Williams hizo énfasis en su investigación, convirtiéndose en una dificultad constante para el desarrollo de los ensayos [36].

Es evidente que en la actualidad no existen manuales que especifiquen metodologías precisas acerca de la elaboración del buffer, cómo saturarlo de $\mathrm{CO}_{2} \mathrm{y}$ cómo comprobar que esta saturación haya quedado correctamente realizada. La recolección del licor ruminal es llevada a cabo de manera poco técnica, sin un protocolo establecido, lo que permite que haya un gran margen de error al realizar la práctica.

Otro aspecto que ya es común y que se menciona en repetidas ocasiones es la necesidad de animales fistulados para la recolección de licor ruminal. Como es bien sabido, todo tipo de procedimiento quirúrgico para una investigación está regido por normas bioéticas, las cuales no aprueban de manera fácil este tipo de procedimientos fuera del cuidado necesario para estos animales en poscirugía y el acompañamiento constante para la prevención de enfermedades que se puedan desencadenar a partir del procedimiento.

En el proceso para resolver estas dificultades se mencionan los experimentos de Jones y Barnes [52], Mauricio [9] y Posada y Rosero [10], quienes han utilizado como alternativa para el inóculo las heces como fuente de microorganismos. Sin embargo, se ha observado que en la experimentación con heces como inóculo son mayores los tiempos de colonización y es menor la capacidad de fermentación, que posiblemente se deba a una menor actividad microbiana en razón a que los microorganismos son originados principalmente en el ciego y el colon y no en el rumen como en la técnica tradicional. La explicación a lo anterior se soporta en que la cantidad de bacterias celulolíticas y otros tipos de microorganismos es mayor en el rumen que en el intestino grueso o en las heces [53, 54]; los inóculos fecales pueden contener algunos hongos anaerobios pero muy poca población de protozoarios [42], y, por último, de alguna manera los microorganismos allí contenidos pueden presentar una menor actividad metabólica en contraste con los situados en el de licor ruminal [55]. Así pues, se logra evidenciar la reducida fermentación en el ciego y el colon con respecto a la que ocurre en el rumen. Por tanto, este inóculo debe ser objeto de mayor investigación.

\section{Conclusiones}

Teniendo en cuenta los criterios a favor y en contra de cada una de las técnicas de digestibilidad de forrajes usadas para la investigación en nutrición animal, se puede evidenciar que la técnica de digestibilidad in vitro de producción de gases es la herramienta más versátil: presenta procedimientos didácticos y accesibles; acarrea menos costos para los investigadores; además representa una alternativa más compatible para las legislaciones de bienestar animal, ya que es innovadora al usar las heces como inóculo. Sin embargo, es necesario realizar más estudios para los inóculos, debido a que sus protocolos no están estandarizados y su comportamiento en las cinéticas realizadas no ha arrojado los resultados esperados.

El uso de estas técnicas va en aumento, pero la experimentación con animales fistulados continuará en el corto y mediano plazo, toda vez que genera información 
directa y confiable acerca del comportamiento del tracto gastrointestinal de los rumiantes, que no se obtiene en las técnicas in vitro.

La técnica in vitro de producción de gases no es el único método que utiliza la tecnología para recrear las cinéticas del rumen en un ambiente externo. Daisy II y Rusitec utilizan este tipo de técnica a pesar de generar mayores costos; teniendo en cuenta que sus equipos son de alto valor económico, necesitan personal técnico capacitado, sumado a que requieren un tiempo prolongado para los ensayos, en contraste con la técnica de producción de gases de costos bajos, de duración del ensayo corta (aproximadamente 96 horas) y el gran número de datos y la repetitividad que se pueden hacer en este bioensayo.

Por último, la técnica representa una alternativa para analizar los forrajes tropicales, de los cuales no existe suficiente información que permita inferir de sus cinéticas de digestión y aprovechamiento por parte de los rumiantes. Además podrá generar información científica que permita la orientación y el aumento del consumo de forrajes en estos animales, y así buscar la mejoría en los rendimientos y desempeños en producción de carne y leche, orientando estos sistemas pecuarios a un mercado más competitivo.

\section{Referencias}

[1] Posada SL, Noguera RR. Técnica in vitro de producción de gases: Una herramienta para la evaluación de alimentos para rumiantes. Livest Res Rural Develop. 2005; 17(4). [Consultado: 7 de junio del 2011]. Disponible en: http://www.lrrd.org/lrrd17/4/posa17036.html

[2] Quin JI, Van der Wath JG, Myburgh S. Studies on the alimentary tract of Merino sheep in South Africa. 4. Description of experimental technique. Onderstrepoort J Vet Sci Anim Ind. 1938; 11: 341-60.

[3] Balch CC, Johnson VW. Factors affecting the utilization of food by dairy cows. 2. Factors influencing the rate of breakdown of cellulose (cotton thread) in the rumen of the cow. Br J Nutr. 1950; 4: 389-95.

[4] Ørskov ER, Hovell D, Mould F. The use of the nylon bag technique for the evaluation of feedstuffs. Trop Anim Health Prod. 1980; 5: 195-213.

[5] Tilley JMA, Terry RA. A two stage technique for the in vitro of forage crops. J Brit Grassland Soc. 1963; 18: 104-11.

[6] Goering H, Van Soest. Forage fiber analysis ARs/USDA Agric. Handbook. 1970; 379.
[7] Cone JW, Beuvink JM, Rodriges M. Use and applications of an automated time related gas production test for In Vitro study of fermentation kinetics in the rumen. Rev Port Zootec. 1994; 1: 25-37.

[8] Menke KH, Raab L, Salewksi A, Steingas H, Fritz D, Schneider W. The estimation of the digestibility and metabolizable energy content of ruminant feeding stuffs from the gas production when they are incubated with rumen liquor in vitro. J Agric Sci. 1979; 93: 217-22.

[9] Mauricio RM. Comparison of bovine rumen liquor and bovine faeces as inoculum for an In vitro gas production technique for evaluating forage. [Ph.D. Thesis]. UK: The University of Reading; 1999: 281.

[10] Posada SL y Rosero. Valoración de las heces y el líquido ruminal como inoculo en la técnica in vitro de producción de gases. Medellín: Universidad de Antioquia; 2006. p. 63.

[11] Pell AN, Schofield P. Computerized monitoring of gas production to measure forage digestion in vitro. J Dairy Sci. Abr 1993; 76(4): 1063-73.

[12] Theodorou MK, Williams BA, Dhanoa MS, Mcallan $\mathrm{AB}$, France JA. Simple gas production method using a pressure transducer to determine the fermentation kinetics of ruminant feeds. Anim Feed Sci Technol. 1994; 48(3-4): 185-97.

[13] Nocek JE. In situ and other methods to estimate Ruminal Protein and Energy Digestibility: a review. J Dairy Sci. 1988; 71(8): 2051-69.

[14] Mertens, DR. Kinetics of cell wall digestion and passage in ruminants. En: Jung HG, Buxton DR, Hatfield RD, Ralph J, editors. Forage cell wall structure and digestibility. American Society Agronomy; 1993. p. 535-70.

[15] Zanton GI, Heinrichs AJ. Evaluation of modeling procedure for fitting in situ feed degradation profiles. J Animal Sci. Jun 2009; 87(6): 2080-8.

[16] Ellis WC, Matis JH, Hill TM, Murphy MR. Methodology for estimation digestion and passage kinetics of forages. En: Fahey GC Jr., Collins M, Mertens DR, Moser LE, editors. Forage Quality, Evaluation and Utilization. American Society of Agronomy; 1994. p. 682-756.

[17] Stern MD, Bach A, Calsamigila S. Alternative techniques for measuring nutrient digestion in ruminants. $J$ Anim Sci. Ago 1997; 75(8): 2256-76.

[18] Noziere P, Michalet-Doreau B. In Sacco methods. En: D’Mello JP, editor. Farm Animal Metabolism and Nutrition. CAB International, Oxon; 2000. p. 233-53.

[19] Winterholller SJ, Lalman DL, Dye TK, Mcmurphy CP, Richards CJ. In situ ruminal degradation characteristics of by-product feedstuffs for beef cattle consuming lowquality forage. J Animal Sci. Sep 2009; 87(9): 2996-3002.

[20] Madsen J, Stensig T, Weisburger MR, Hvelplund T. Estimation of the physical fill of feedstuffs in the rumen 
by the in sacco degradation characteristics. Livest Prod Sci. 1994; 39: 43-47.

[21] Meyer JH, Mackie RI. Microbiological evaluation of the intraruminal in sacculus digestion technique. Appl Environ Microbiol. Mar 1986; 51(3): 622-9.

[22] Noziere P, Michalet-Doreau B. Validation of in sacco method: influence of sampling site, nylon bag or rumen contents, on fibrolytic activity of solid-associated microorganisms. Anim Feed Sci Technol. 1996; 57(3): 203-10.

[23] Michalet-Doreau B. New methods for estimating forage feed values: in sacco. En: XVIth International Grassland Congress, Nice. AFPF, INRA, Route de St-Cyr, Versailles; 1990. p. 1850-1852.

[24] Crampton EW. Applied animal nutrition. San Francisco: Freeman; 1956. p. 458.

[25] Raymond WF, Harris CE, Harker VG. Studies on the digestibility of herbage. I. Technique of measurement of digestibility and some observations of factor affecting the accuracy of a digestibility data. J Brit Grassland Soc. 1953; 8(4): 301-14.

[26] Blaxter KL. The energy metabolism of ruminats. London: Hutchnson; 1962. p. 329.

[27] Maynard LA. Animal nutrition. 3rd. ed. New York: McGraw-Hill; 1951. p. 474.

[28] Galina MA et al. Cinética ruminal y crecimiento de cabritos suplementados con un probiótico de bacterias ácido-lácticas. Pastos y Forrajes [online]. 2009; 32(4): 1. [Consultado: 6 de octubre del 2011]. Disponible en: $<$ http://scielo.sld.cu/scielo.php?script=sci_arttext\&pid $=$ S0864-03942009000400009\&lng=en\&nrm=iso $>$

[29] Barnicoate CR, Estimation of apparent digestibility coefficients by means of an inert "reference-substance". New Zealand Science and Technology. 1945; 2: 202-12.

[30] Weiss WP. Estimation of digestibility of forages by laboratory methods. En: Fahey GC Jr., Collins M, Mertens DR, Moser LE, editors. Forage Quality, Evaluation and Utilization. American Society of Agronomy; 1994. p. 644-81.

[31] Firkins JL, Allen MS, Oldick BS, St-Pierre NR. Modeling ruminal digestibility of carbohydrates and microbial protein flow to the duodenum. J Dairy Sci. 1998; 81: 3350-69.

[32] Menke KH, Steingas H. Estimation of the energetic feed value obtained from chemical analysis and in vitro gas production using rumen fluid. Animal Research and Development. 1988; 28: 7-55.

[33] Mauricio RM, Mould FL, Dhanoa MS, Owen E, Channa KS, Theodorou MK. A semi-automated in vitro gas production technique for ruminant feedstuff evaluation. Anim Feed Sci Technol. 1999; 79: 321-30.
[34] Beuvink JM, Spoelstra SF, Hogendorp J. An automated method for measuring time-course of gas production of feedstuffs incubated with buffered rumen fluid. Nether J Agric Sci. 1992; 40: 401-7.

[35] Doane PH, Schofield P, Pell AN. NDF disappearance. Gas and VFA production during In vitro fermentation of six forages. J Anim Sci. Dic 1997; 75(12): 3342-52.

[36] Williams BA. Cumulative gas-production techniques for forage evaluation. En: Givens DI, Owen E, Omed HM, Axford RFE, editors. Forage Evaluation in Ruminant Nutrition. Wallingford (UK) САВ International; 2000. p. 475.

[37] Grant RJ, Mertens DR. Development of buffer systems for $\mathrm{pH}$ control and evaluation of $\mathrm{pH}$ effects on fiber digestion In vitro. J Dairy Sci. Jun 1992; 75(6): 1581-87.

[38] Schofiled P. Gas production methods. En: Farm Animal Metabolism and Nutrition. Wallingford (UK). СAB International; 2000. p. 450.

[39] Opatpatanakit Y, Kellaway RC, Lean IJ, Annison G, Kirby A. Microbial fermentation of cereal grains in vitro. Aust J Agric Res. 1994; 45(6): 1247-63.

[40] Schofiled P, Pitt RE, Pell AN. Kinetics of fiber digestion from in vitro gas production. J Anim Sci. Nov 1994; 72(11): 2980-91.

[41] Makkar H, Recent advances in In vitro gas method for evaluation of nutritional quality of feed resources. 2001 [Consultado: 18 de octubre del 2011]. Disponible en: http://www.fao.org/DOCREP/ARTICLE/ AGRIPPA/570_EN_toc.htm

[42] Davies ZS, Mason D, Brooks AE, Griffith GW, Merry RJ, Theodoru MK. An Automated System for Measuring Gas Production from Forage Inoculated with Rumen Fluid and its use in Determining the Effect of Enzymes on Grass Silage. J Anim Feed Sci Technol. 2000; 83: 205-21.

[43] Valencia D, Giraldo L. Cinética de la degradación ruminal in vitro de forrajes suplementados con glicerina cruda proveniente de la obtención de biodiesel del aceite de palma africana. Rev Colom Cienc Pecua. 2009; 22: 3.

[44] Czerkawzky JW, Breckenridge G. Design of a long-term simulation technique (Rusitec). Brit J Nutr. Nov 1977; 38(3): 371-84.

[45] Pashaei S, Razmazar V, Mirshekar R. Gas Production: A Proposed in vitro method to Estimate the Extent of Digestion of a Feedstuff in the Rumen. J Biol Sci. Sep 2010; 10(6): 573-80.

[46] Grings EE, Blümmel M, Sudekum KH. Methodological considerations in using gas production techniques for estimating ruminal microbial efficiencies for silage based diets. J Anim Feed Sci Technol. Sep 2005; 123(1): 527-45. 
[47] Pell AN, Doane PH, Schofiled P. In vitro digestibility and gas production. En: Simpósio sobre Tópicos Especiais em Zootecnia. Lavras, MG; 1997. p. 109-32.

[48] Nsahlai IV, Umunna NN, Negassa D. The effect of multi-purpose tree digesta on in vitro gas production from napier grass or neutral-detergent fibre. J Sci Food Agric. 1995; 69: 519-28.

[49] Getachew G, Blümell M, Makkar HP, Becker K. In vitro measuring techniques for assessment of nutritional quality of feeds: a review. Anim Feed Sci Technol. Jun 1998; 72(3-4): 261-81.

[50] Ørskov ER, Reid GW, Kay M. Prediction of intake by cattle from degradation characteristics of roughages. Animal. Feb 1988; 46(1): 29-34.

[51] Liu Jian Xin, Susenbeth A, Sudekum KH. In vitro production measurements to evaluate interactions between untreated and chemically treated rice straws, grass hay, and mulberry leaves. J Anim Sci. Feb 2002; 80(2): 517-24.
[52] Jones RJ Barnes P. In vitro digestibility assessment of tropical shrub legumes using rumen fluid or fecal fluid as the inoculum source. Trop Grasslands. 1996; 30: 374-77.

[53] El-Meadaway A, Mir Z, Zaman PS. y Yanke LJ., Relative efficacy of inocula from rumen liquor and fecal solution for determining In vitro digestibility and gas production. J Anim Sci. 1998; 78: 673-9.

[54] Omed HM, Lovett DK, Axford RFE. Faeces as Source of Microbial Enzymes for Estimating Digestibility. En: Givens DI, Owen E, Axford RFE, Omed HM, editors. Forage Evaluation in Ruminal Nutrition. Wallingford (UK): CABI Publishing; 2000. p. 135-54.

[55] Mauricio RM, Owen E, Mould FL, Givens I, Theodorou MK, France J, Davies DR, Dhanoa MS. Comparison of bovine rumen liquor and bovine faeces as inoculum for an in vitro gas production technique for evaluating forages. Anim Feed Sci Technol. 2001; 89(1-2): 33-48. 